\title{
The Effect of NLP (Accelerated Learning) on Iranian EFL Learner's Listening Comprehension
}

\author{
Chnour Khalandi \\ New Talent Cambridge Preparation Center, Tabriz, Iran \\ Rashideh Zoghi \\ English Department, Islamic Azad University, Tabriz Branch, Iran
}

\begin{abstract}
Neuro-Linguistic Programming (NLP) strategies and specifically Accelerated Learning on Iranian EFL learner's listening comprehension and detailed listening. To fulfill the purpose of this study, a total number of 30 Iranian EFL learners studying as Cambridge ESOL KET students were selected through stratified sampling procedure. They were divided in two control and experimental groups with 10 and 20 learners in each group respectively. Each group took a VAK questionnaire, a pre -test and a treatment process of 12 sessions and a posttest. In the experimental group the teacher conducted a set of short videos and mixed methods based on Accelerated Learning as one of neuro linguistic programming techniques. In control group a set of limited short videos conducted. On the last session, the participants of both groups took a post- test to measure their achievement of listening comprehension and detailed listening. This research suggests that accelerated learning is much more dynamic and has a significant effect on listening comprehension, detailed listening and, different learning styles, which hypothesizes that all VAK learner's language processing follow one another in a strictly accelerated manner. Statistically, the effect of accelerated learning on visual, auditory and kinesthetic learner's listening comprehension is 87,93 and 85 percent respectively.
\end{abstract}

Index Terms - accelerated learning, listening, NLP, VAK

\section{INTRODUCTION}

Pedagogical researches have shown that the perception of information according to the manner and pace of understanding, and learning conditions differs from person to person. Therefore, it is essential for teachers to attempt to find effective ways to teach their students and come up with some practical learning strategies for their English/language classes in order to place a priority on the learning preferences of their learners (Carbo, 1981). NeuroLinguistic Programming (NLP) was developed at the University of California at Santa Cruz in 1970's. Richard Bandler, and John Grinder were the founders and principal authors. Applying NLP techniques to Language learning processes facilitates exerting an influence on the learners mind through the use of language and other means of communication and consequently, enables learners to rearrange mentally the way the brain reacts to a stimulus, and works towards a change for the better as well as novel behavior patterns. (Tosey-2003). Dr. Richard Bandler came up with the term "Neuro-Linguistic Programming" in the 1970s. The definition of "Neuro-Linguistic Programming" (NLP) by Dr. Richard Bandler appears in the Oxford English Dictionary (Bruce; Pignotti, Monica, 2015). He defines it as:

"Neuro-Linguistic Programming is a technique of communication between people. Specifically, it's related to the connection between successful models of behaviour and personal experiences underlying them; it's a system of alternative activities to train people to be self-aware, improve their communication skills effectively, and work on their patterns of mental as well as emotional behavior "(Hastings, 2009).

Many language teachers have been using NLP and it's techniques for many years unconsciously. Since the discovery of NLP, a lot of new teaching methods which follow the NLP guidelines have been adopted, such as some elements of drama, music, and body language that are now being applied to second language teaching globally (Bergen \& Soper, 1997). Pedagogical roots of NLP indicate the human brain's performance as well as the manner in which it engages in self-improvement. Such activities are attributable to Left-hand side brain that, along with visual-auditory-kinesthetic learning style, multiple intelligence (Gardner, 1991), and other fields of study investigate not only teaching models employed by teachers, but also learning tastes of each individual learner (Alan Chapman, 2017).

Many descriptive and experimental studies have investigated NLP in second language teaching to demonstrate how it can work towards a change for the more remarkable achievements in the area of education specifically, when teachers are involved in helping their learners with second language acquisition (Lankton, 1979).

Hill (1973, as cited in Bandler and Grinder, 1982) is considered a pioneer in evaluation of an individual's modes of behavior when he/she looks for meaning. He introduced sensory channels as a means of processing an individual's abilities. According to him, visual, auditory and kinesthetic channels are among the most important sensory channels. Employing all three modalities involves cognitive maturity. Traditional approaches to teaching languages such as audio- 
lingual, grammar translation, communicative language teaching, and formalism have increased second language teachers and learners' workload.

One of these approaches is "Neuro-Linguistic Programming" (NLP). Although it is not considered a teaching approach, it is a new technique. The premise of NLP is that we hope for effective learning outcomes in the area of SLA. Debates about applying different NLP techniques to second language teaching has resulted in major achievements in the area of second language acquisition (Moeller, 2015).

In recent years, NLP has been in a stronger position in education due to its effectiveness in helping learners gain a better understanding of the ways they employ to acquire a new language. In 1983, the theory of multiple intelligence was put forward by Howard Gardner. According to this theory, learning styles can be classified into three main categories: visual, in which learners respond better to the visual stimuli such as watching videos, giving a demonstration, doing reading activities, and understanding charts; auditory, in which learners learn more when they have material explained to them; and kinesthetic, in which learners learn better when they perform an activity, such as conducting experiments and being involved in practical experiences. Teachers are now increasingly applying NLP techniques to their classrooms for the benefit of each individual learner. Some universities also recently have adopted NLP techniques to deal with students learning problems. (Schneider, 2017).

This new technique explains how one processes information which comes to them from the outside. Neuro-linguistic Programming is viewed as a general approach to life, including the study of language acquisition. (Frieden, 1981). The major reason for conducting the present study is to discover whether Neuro-linguistic Programming as a new supplementary teaching approach can facilitate the acquisition of English. This study also examines the effects of accelerated learning on listening comprehension and detailed listening progress/problems/process????? of Iranian EFL learners. The following research questions are set to help us conduct the present survey:

RQ1: Does accelerated learning have any effect on listening comprehension of Iranian EFL learners?

RQ2: Does accelerated learning have any effect on detailed listening of Iranian EF L learners?

The American psychologist Steven Pinker describes that imagining human life without language is scarcely possible because language is merged with human experience. Language is a system of communication used by humans everywhere and is undoubtedly one of the main noticeable and easily manifested aspects that differentiate human beings from the rest of the animal kingdom (Zoghi, 2017).

The main purpose of NLP is to help people understand and control their thoughts and feelings to build up positive changes in their lives specifically in sphere of education during learning process. It also helps teachers identify learning styles of their learners. Studies on the function of brain and learning process in different people have made NLP integrate into ELT (Darn, 2006)

In order to guide the use of rapid and effective behavioural modification, and an operational philosophy, NLP consists of a set of powerful techniques which are based on three operational principles (Daniel, 2001):

1. To know what outcome you want to achieve.

2. To step forward to the outcome.

3. To behave flexible to get the out come

To end up with specific outcomes is very important. Wandering randomly through life and not having conscious outcomes happen to many people. The importance of living with conscious purpose is stressed by NLP. It teaches a series of linguistic and behavioural patterns that help people change the beliefs and behaviours of others effectively. (Smith, 2012).

Moreover, another factor that learning a new language is significantly affected by, is Accelerated learning (A.L) which is a system to speed up and enhance both the design and the learning processes. It has proven over and over to increase learning effectiveness while saving time and money in the process according to the latest brain research. Its effectiveness comes from the way we all naturally learn. The main role of accelerated learning is to untap the potential for learning by most conventional learning methods and actively involving the whole person, using physical activity, creativity, music images, and a total mixed method which suites three kinds of learners (visual, auditory, kinesthetic) (Meier, 2017).

Many factors such as; positive learning environment, total learner involvement, collaboration among learners, variety that appeals to all preferences, make accelerated learning as an optimal learning environment to conduct the main aim which is to get the results. The following are some principles of accelerated learning:

1. To involve whole mind and body

2. To consider learning and knowledge as creation, not consumption or absorbing something.

3. To collaborate with peers.

Meanwhile, learners are naturally born with a set of intelligence types, and their intelligences vary across different individuals in a way that some learners, for example, may excel in one or more intelligence types while they may lag behind the other learners in some other types of intelligences (Stanford, 2016).

Moreover, Fleming's (1995) VAK model puts learning preferences into three main categories: visual learning style, in which learners do best when they watch videos and charts or read; auditory learning in which, the learner prefers to be explained what to do, and kinesthetic learners who learn best by touching, moving or feeling things such as doing experiments and taking part in practical lessons (Zoghi, 2017). 
One of the many characteristics that make up a learners learning style is representational systems also known as sensory modalities. As already mentioned in previous parts, there are three major sensory modalities known as visual, auditory, and kinesthetic collectively abbreviated to VAK which is an inevitable model of neuro-linguistic programming in sense of processing, representing, coding, and storing information in human mind. Sensorial representation of experiences in the mind is the main domain of this model. Moreover, human being experiences the world around through his five senses: visual, auditory, kinesthetic, gustatory, and olfactory. Each individual uses all these senses all of the time but depending on circumstances may focus on one or more of them. In general, one representational system is not better than the other one and depending on the situation or the task that we are doing or learning, one representational system might be more effective than the other. (Ellerton, 2015).

Some studies have focused on the role of VAK preferences in learning generally and second or forging language particularly. For example, Farooque, Mustafa, and Mohammad (2014) investigated the learning style preferences of first year undergraduate medical students. The results of this study showed that there was no significant difference in learning preferences between the genders. In a similar study conducted by Marwah, Bhagat, and Kapoor (2015) the learning preferences of undergraduate dental students of a north Indian dental college was investigated. The results showed diversity in learning styles or preferences of the learners.

There have also been some studies on NLP, accelerated learning and listening comprehension of second or forging languages learners. For instance, in Iranian EFL context, Davoudi and Chavosh (2016), conducted a study on the relationship between multiple intelligence and listening self-efficacy among Iranian EFL learners. Some of the studies have attempted to find out either the effect of NLP or its relationship with learning language skills and components. Moharamkhani, Karimi, and Ahmadi (2016) have studied the impact of Neuro Linguistic Programming (NLP) on EFL learners' vocabulary achievement.. The results revealed that neuro linguistic programming had significant impact on EFL learners' vocabulary achievement. Furthermore, Moharamkhani, Karimi and Ahmadi (2016) investigated The Impact of NeuroLinguistic Programming (NLP) on EFL Learners' Vocabulary Achievement. The mentioned researchers came to the conclusion that neuro linguistic programming had significant impact on EFL learners ${ }^{\text {ce }}$ vocabulary achievement.

In the present experimental correlational study there are three variable, accelerated learning as independant, listening comprehension, and detailed listening as dependant varaible. The researcher wanted to find out if accelerated learning has any effect on listening comprehension and detailed listening of Iranian EFL learners and consequently language learning process.

\section{METHODOLOGY}

\section{Participants}

To fulfill the purpose of this study, a total number of 30 Iranian EFL learners studying as Cambridge ESOL KET students were selected through stratified sampling procedure.

\section{Instruments}

In this quantitative correlational experimental study VAK questionnaire, a pre -test and a treatment process of 12 sessions were conducted. In the experimental group, the teacher administered a set of short videos and mixed methods based on Accelerated Learning as one of neuro linguistic programming techniques. In control group a set of limited short videos were conducted. On the last session, the participants of both groups took a post- test to measure their achievement of listening comprehension and detailed listening.

Each group took a VAK questionnaire (Appendix I), videos and their multiple choice tests and slots of Learn English British Council Episodes (Appendix II). The VAK questionnaire developed by Victoria Chislett (2005), includes 30 multiple choice questions tagged as A, B, and C. learners with mostly A's, B's and C's have a visual, auditory and kinesthetic learning style respectively. A pilot study with 20 sample respondents was conducted in order to ensure the validity of the questionnaires. The reliability analysis of the questionnaire revealed an acceptable range of reliability for visual, auditory, and kinesthetic preferences questions.

The videos and related multiple choice, descriptive questions and slots of Learn English British Council Episodes were administered as pre_test, treatment and post_test. The results fed in to SPSS software.

Procedure

To conduct this study each group took the VAK questionnaire. It took 40 minutes for respondents to fill it. This questionnaire includes a total number of 30 questions each of which has 3 options of as $\mathrm{A}, \mathrm{B}$, and $\mathrm{C}$. The respondents were supposed to choose the option which best suited them. After finishing the responding process, the researcher identified the respondents' preference by counting As as auditory, Bs as visual, and Cs as kinesthetic learning style.

Moreover, three videos were projected at the next session, each lasted 15 minutes and then a set of difficult gap space with new vocabulary and sentence completion, five questions for each video were administered as pretest of both groups. Most of them couldn't answer half of the questions. Their listening tasks were checked and no other listening tasks were administered instead they followed the same normal process of studying their course book. Finally, at the $12^{\text {th }}$ session the same videos and questions were projected again as post-test. Some of the students had already been looking for new words that were in gap space out of the class but yet they couldn't answer half of the questions. 
Furthermore, same videos with same questions were administered for experimental group at first session and the results were the same. To conduct the project, the videos of Learn English British Council and their tasks were administered for 12 intensive sessions. The results indicated the learner's listening skill improvement day by day, while in each lesson the questions were more difficult than the previous session's. At the last session, same videos including the same questions for pre-test, were administered as post-test. The learners could explain what the videos were about using new vocabulary and even words from gap spaces.

\section{RESUltS}

As mentioned in the previous part, the results fed in to SPSS software. To test the first research question ANCOVA was conducted. Some assumptions should be met before applying ANCOVA. The first assumption regards the normal distribution of the data. One-Sample Kolmogrov-Smirnov Test was used for examining the normal distribution of the data. The results are given in Table1.

TABLE 1

ONE-SAMPLE KOLMOGOROV-SMIRNOV TEST FOR NORMAL DISTRIBUTION OF THE SCORES IN 2 GROUPS IN PRETEST AND POST TEST

\begin{tabular}{llc}
\hline & Pre Test & post test \\
\hline $\mathrm{N}$ & 30 & 30 \\
Kolmogorov-Smirnov Z & .748 & .919 \\
P value & .631 & .367 \\
\hline
\end{tabular}

As the results in Table 1 indicate, the significance level in both pretest and posttest is higher than the p value of .05 $(p=.631 \& .367>.05)$ indicating normal distribution of the scores.

Moreover, Leven's Test of Equality of Error variance for 2 groups was carried out to examine the equality of variances. The results are given in Table 2:

TABLE 2

LEVENE'S TEST OF EQUALITY OF ERROR VARIANCES FOR SCORES IN POSTTEST IN 2 GROUPS

\begin{tabular}{llll}
\hline $\mathrm{F}$ & df1 & df2 & P value \\
\hline 5.83 & 1 & 27 & .067 \\
\hline
\end{tabular}

As the results in Table 2 indicates, the equivalence of the variances across posttest is confirmed $(\mathrm{F}=5.83, \mathrm{P}=.067>.05)$ meeting the assumption of equal distribution of the scores between the 2 groups.

Moreover, regression analysis was conducted in order to examine the slope of regression for the scores in posttest which yielded the results given in Table 3:

TABLE 3

COVARIANCE TO EXAMINE THE SLOPE OF THE REGRESSION FOR SCORES IN POSTTEST IN 2 GROUPS

\begin{tabular}{llllll}
\hline Source & Type III Sum of Squares & Df & Mean Square & F & P value \\
\hline Group * Pretest score & 465.939 & 2 & 232.970 & 2.973 & .069 \\
Error & 1959.345 & 25 & 78.374 & & \\
\hline
\end{tabular}

As the results in Table 3 shows, examining the interaction of experimental group Pretest score in predicting the dependent variable or post test score indicated that the interaction effect is not meaningful $(\mathrm{f}=2.97, \mathrm{p}=.069>.05)$. In other words, there is not a meaningful interaction between the independent variable and the intervening variable, and ANCOVA can be conducted with the assumption of the homogeneity of the slopes.

TABLE 4

ANALYSIS COVARIANCE TO COMPARE THE POSTTEST SCORES IN EXPERIMENTAL AND CONTROL GROUPS

\begin{tabular}{|c|c|c|c|c|c|c|c|}
\hline Source & Type III Sum of Squares & Df & Mean Square & $\mathrm{F}$ & $P$ value & $\begin{array}{l}\text { Partial Eta } \\
\text { Squared }\end{array}$ & $\begin{array}{l}\text { Observed } \\
\text { Power }\end{array}$ \\
\hline Group & 10410.848 & 1 & 10410.848 & 120.898 & .000 & .823 & 1.000 \\
\hline Pre test & 186.353 & 1 & 186.353 & 2.164 & .153 & .077 & .294 \\
\hline Error & 2238.931 & 26 & 86.113 & & & & \\
\hline
\end{tabular}

As the results in Table 4 show, the group effect is significant $(\mathrm{F}=120.8, \mathrm{P}<.05)$. Eta squared is .82 and the observed power is 1.00 meaning that the analysis is 100 percent correct in exploring the significant differences.

Moreover, as the results in Table 5 show, pretest scores have been controlled. In other words, the effect of pretest scores has been eliminated from post test scores, and the 3 groups are compared with each other based on the residual variances. 
TABLE 5

DESCRIPTIVE STATISTICS FOR SCORES IN EXPERIMENTAL AND CONTROL GROUPS IN PRETEST, POSTTEST AND FINAL ESTIMATE (POSTTEST) AFTER CONTROLLING PRETEST

\begin{tabular}{lllllll}
\hline & \multicolumn{2}{c}{ Pre test } & & Post test & & \multicolumn{2}{c}{$\begin{array}{l}\text { Post test } \\
\text { Final estimate }\end{array}$} \\
\cline { 2 - 7 } & Mean & Std. Deviation & Mean & Std. Deviation & Mean & Std. Error \\
\hline Control & 31.30 & 6.515 & 35.20 & 7.842 & 37.53 & 3.337 \\
Experimental & 41.00 & 7.431 & 87.35 & 10.297 & 85.50 & 2.287 \\
\hline
\end{tabular}

As the results in Table 5 show, the mean pretest score for control group is 31.3 and experimental group is 41 . The mean post test scores for control group 35.2 and experimental group is 87.35.

The mean scores, after controlling the intervening variables is 37.53 for control group and 85.5 for experimental group $(\mathrm{F}=120.8, \mathrm{P}<.05)$.

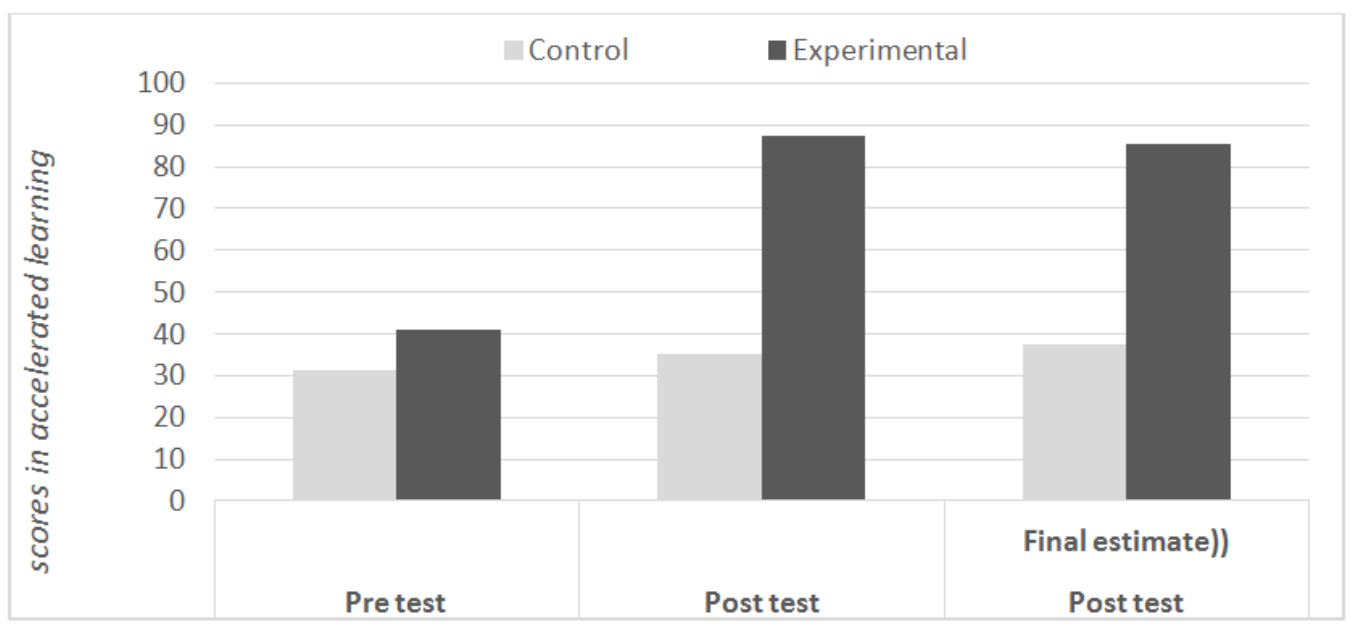

Fig1. scores of 2 groups

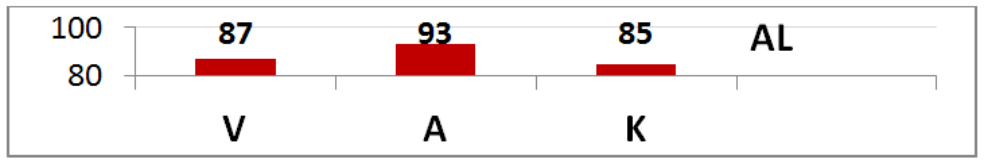

Fig2. the effect of accelerated learning on VAK preferences

\section{DISCUSSION}

The present study was launched with the purpose of examining the effect of accelerated learning on Iranian EFL learners listening comprehension.

The two research questions on the effectiveness of accelerated learning on listening comprehension and detailed listening of Iranian EFL learners were tested. It was found that accelerated learning is highly correlated with listening comprehension and detailed listening of the learners indicating that accelerated learning is much more dynamic and has a significant effect on different learning styles, which hypothesizes that all VAK learner's language processing follow one another in a strictly accelerated manner. Statistically, the effect of accelerated learning on visual, auditory and kinesthetic learner's listening comprehension is 87,93 and 85 percent respectively. This is the point already endorsed by Brown (1987), Ellis (1994), Walqui (2000), Hoekstra (2009). The mentioned authors have emphasized learning styles to improve learning process. This also calls for the consideration of individual learning factors and individual instruction as stressed by Lyal (2002) and Dunn and Burke (2006) besides the others (Zoghi, 2017).

In terms of the existence of a correlation between accelerated learning and listening comprehension and detailed listening, the findings of this study are in line with the findings of the study by Davoudi and Chavosh (2016), Saricaoglu and Arikan's (2009), and Derakhshan and Faribi (2015). Lashkarian and Sayadian (2015) studied the The Effect of Neuro Linguistic Programming (NLP) Techniques on Young Iranian EFL Learners' Motivation, Learning Improvement, and on Teacher's Success. The results emphasized the importance of NLP techniques in EFL settings by enabling the teacher to communicate better with students, strengthen the learning environment, and develop positive interaction that would increase academic effectiveness, motivation and proficiency of learners.

The results of this study were also in line with the findings of Habibinezhad and Azizmalayeri (2016) who studied the impacts of accelerated learning and explicit instruction on the retention and application of lexical bundles in writing. The results of the study revealed that accelerated learning of lexical bundles did enhance EFL learners writing ability. However, it should be stated that other studies revealed the effectiveness of the explicit instruction of lexical bundles to improve the writing skills of language learners. 


\section{CONCLUSION AND IMPLICATION}

The present study attempted to investigate the effects of accelerated learning and listening comprehension of Iranian EFL learners. The study revealed the fact that the accelerated learning of experimental gruop was fruitful to language learners and had a positive effect on the dependent variable of the study, namely, the listening skill of the language learners.

The findings of the study show that the accelerated learning of mixed methods can be fruitful for language learners if it is employed in the Iran's educational system. In line with the findings of the present study, the previous studies show that the use of accelerated learning provides benefits to language learners (Rose, 2003; Silberbach, 2007). It also states that accelerated learning provides greater range of support and different activities for language learners in the process of language learning in general and four skills in particular. The study also reveals the fact that identifying the learning styles or learning preferences, the teacher can create a learning environment in which every individual learner flourishes.

Accordingly, it should be stated that the accelerated learning addresses individual learner needs and learner preferences which is suited best with this post-method era. Materials designers, language educators and teachers are advised to first estimate their learners' preferred learning style and adapt their teaching/learning tasks accordingly. The textbooks can be designed in such a way that encourages language learners to employ course books as a contributing device to accelerate their process of communication and learning process. Furthermore, more studies may be conducted with different age groups and various fields of study in different learning contexts. Other researchers may be interested also in studying the effect of other techniques of NLP on VAK preferences, focusing on other proficiency level learners, studying the effects of other techniques of NLP on four skills, and studying the relationship between personality type and VAK preferences.

\section{APPENDIX I. VAK PREFERENCES QUESTIONNAIRE}

VAK Learning Styles Self-Assessment Questionnaire Circle or tick the answer that most represents how you generally behave.

1. When I operate new equipment I generally:

a. read the instructions first

b. listen to an explanation from someone who has used it before

c. go ahead and have a go, I can figure it out as I use it

2. When I need directions for travelling I usually:
a. look at a map
b. ask for spoken directions
c. follow my nose and maybe use a compass

3. When I cook a new dish, I like to:
a. follow a written recipe
b. call a friend for an explanation
c. follow my instincts, testing as I cook

4. If I am teaching someone something new, I tend to:
a. write instructions down for them
b. give them a verbal explanation
c. demonstrate first and then let them have a go

5. I tend to say:
a. watch how I do it
b. listen to me explain
c. you have a go

6. During my free time I most enjoy:
a. going to museums and galleries
b. listening to music and talking to my friends
c. playing sport or doing DIY

7. When I go shopping for clothes, I tend to:
a. imagine what they would look like on
b. discuss them with the shop staff
c. try them on and test them out

8. When I am choosing a holiday I usually:
a. read lots of brochures
b. listen to recommendations from friends
c. imagine what it would be like to be there

9. If I was buying a new car, I would:

a. read reviews in newspapers and magazines

b. discuss what I need with my friends 
c. test-drive lots of different types

10. When I am learning a new skill, I am most comfortable:

a. watching what the teacher is doing

b. talking through with the teacher exactly what I'm supposed to do

c. giving it a try myself and work it out as I go

11. If I am choosing food off a menu, I tend to:
a. imagine what the food will look like
b. talk through the options in my head or with my partner
c. imagine what the food will taste like

12. When I listen to a band, I can't help:
a. watching the band members and other people in the audience
b. listening to the lyrics and the beats
c. moving in time with the music

13. When I concentrate, I most often:
a. focus on the words or the pictures in front of me
b. discuss the problem and the possible solutions in my head
c. move around a lot, fiddle with pens and pencils and touch things

14. I choose household furnishings because I like:
a. their colours and how they look
b. the descriptions the sales-people give me
c. their textures and what it feels like to touch them

15. My first memory is of:
a. looking at something
b. being spoken to
c. doing something

16. When I am anxious, I:
a. visualize the worst-case scenarios
b. talk over in my head what worries me most
c. can't sit still, fiddle and move around constantly

17. I feel especially connected to other people because of:
a. how they look
b. what they say to me
c. how they make me feel

18. When I have to revise for an exam, I generally:
a. write lots of revision notes and diagrams
b. talk over my notes, alone or with other people
c. imagine making the movement or creating the formula

19. If I am explaining to someone I tend to:
a. show them what I mean
b. explain to them in different ways until they understand
c. encourage them to try and talk them through my idea as they do it

20. I really love:

a. watching films, photography, looking at art or people watching

b. listening to music, the radio or talking to friends

c. taking part in sporting activities, eating fine foods and wines or dancing

21. Most of my free time is spent:
a. watching television
b. talking to friends
c. doing physical activity or making things

22. When I first contact a new person, I usually:
a. arrange a face to face meeting
b. talk to them on the telephone
c. try to get together whilst doing something else, such as an activity or a meal

23. I first notice how people:
a. look and dress
b. sound and speak
c. stand and move

24. If I am angry, I tend to:

a. keep replaying in my mind what it is that has upset me

b. raise my voice and tell people how I feel 
c. stamp about, slam doors and physically demonstrate my anger

25. I find it easiest to remember:
a. faces
b. names
c. things I have done

26. I think that you can tell if someone is lying if:

a. they avoid looking at you

b. their voices changes

27. When I meet an old friend:
a. I say "it's great to see you"!
b. I say "it's great to hear from you"!
c. I give them a hug or a handshake

28. I remember things best by:
a. writing notes or keeping printed details
b. saying them aloud or repeating words and key points in my head
c. doing and practicing the activity or imagining it being done

29. If I have to complain about faulty goods, I am most comfortable:
a. writing a letter
b. complaining over the phone
c. taking the item back to the store or posting it to head office

30. I tend to say:
a. I see what you mean
b. I hear what you are saying
c. I know how you feel

Now add up how many A's, B's and C's you selected.

$\mathrm{A}^{\prime} \mathrm{s}=\mathrm{B}$ 's $=\quad \mathrm{C}^{\prime} \mathrm{s}=$

If you chose mostly A's you have a VISUAL learning style.

If you chose mostly B's you have an AUDITORY learning style.

If you chose mostly C's you have a KINAESTHETIC learning style.

\section{APPENDIX II}

http://learnenglish.britishcouncil.org/en/listening-skills-practice http://learnenglish.britishcouncil.org/en/starting-out /Episodes

\section{REFERENCES}

[1] Ahmadian, M., \& Hosseini, S. (2012). A study of the relationship between Iranian EFL learners Multiple Intelligences and their performance on writing. Mediterranean Journal of Social Sciences, 3(1). Doi:10.5901/mjss.2012.03.01.111.

[2] Alavinia, P., \& Ebrahimpour, S. (2012). On the correlation between emotional intelligence and learning styles: the case of Iranian academic Eel learners, Theory and Practice. Language Studies, 2(6), 1291-1299.

[3] Anita, L., and Sayadian, S., (2015). The Efect of Neuro Linguistic Program ming (NLP) Techniques on Young Iranian EFL Learner s' Motivation, Learning Improvement, and on Teacher's Success. Procedia - Social and Behavior al Sciences, 199, 2017.

[4] Armstrong, T. (1994). Multiple Intelligence in the classroom. Alexandria, VA: The Association of Supervision and Curriculum Development.

[5] Bergen, C. W., Soper, B., Rosenthal, G. T. \& Wilkinson, L. V. (1997), 'Selected Alternative Training Techniques in HRD',18, pp. 281-294.

[6] Brown, B. L. (1996). Learning styles and vocational education practice. U.S. Department of Education, Office of Educational Research and Improvement, Practice Application Briefs.

[7] Bruce A.; Pignotti, Monica G. (2015). Neuro-linguistic programming - Revolvy. Retrieved from https://www.revolvy.com/main/index.php?s=Neuro...item_type=topic.

[8] Burstein, J. (2009). Opportunities for Natural Language Processing Research in Education. International Conference on Intelligent Text Processing and Computational Linguistics, pp 6-27.

[9] Chapman, A., (2017). Teaching NLP in the Classroom. The free online team building and motivational training resource. Retrieved from https://jekarcoco.files.wordpress.com/2017/09/teaching-nlp-in-the.pdf, 2017

[10] Canning, C. (2000). Visual research. Invited presentation for the TESOL Arabia Special Interest Group, Hilton Ballroom.

[11] Carbo, M. (1981). Reading Style Inventory Manual. New York: Learning Research Associates

[12] Çetin, Y. (2009). Teaching VAK-abulary. Paper presented at the 1st International Symposium on Sustainable Development, Sarajevo, Bosnia and Herzegovina.

[13] Christison, M. A. (1999). Multiple Intelligences. ESL Magazine, 2(5), 10-13.

[14] Cronin, M. \& Myers S. (1997). The effects of visuals versus no visuals on learning outcomes from Interactive multimedia instruction, Journal of Computing in Higher Education. 8(2), 46-71

[15] Csikszentmihaly, M. (1990). Flow: The psychology of optimal experience. New York: Harper/Collins. 
[16] Csikszentmihaly, M. (1996). Creativity: Flow and the psychology of discovery and invention. New York: Harper/Collins.

[17] Beck, D., (2001). Approach in Natural Language Processing (NLP). Department of Linguistics and Philology. University of Sheffield, United Kingdom.

[18] Darn, S., (2005). Neuro Linguistic Programming in ELT. Izmir University of Economics, Turkey.

[19] Davies, J. (1996) [On-line\} "A reluctant guru on matters between the ears. Howard Gardner talks to John Davies about his theory of human intelligence." (Original published in The Thesis, January 19, 1996).

[20] Davoudi, M. \& Chavosh, M. (2016). The Relationship between multiple intelligences and listening self-efficacy among Iranian EFL learners. English Language Teaching, 9(6), 199-200.

[21] Dehghan Harati, R. (2011). Learner beliefs, teacher beliefs: Are they different? Iranian EFL Journal, 7(5), 190-221.

[22] Derakhshan, A. \& Faribi, M. (2015). Multiple intelligences: Language learning and teaching. International Journal of English Linguistics, 5(4), 16-19.

[23] Dilts, R. D. \& Epstein, T., Dilts R., W. (2011). NLP and the creativity. Alessio Roberti, Roma, Italy.

[24] Dunn, R. \& Burke, K. (2006). Research and implementation manual. International Learning Styles Network. Available at http//:www.learningstyles.net/En/user-home (20016).

[25] Ellis, R. (1994). The study of second language acquisition. Oxford: Oxford University Press.

[26] Ellertone, R., (2015) NLP and Personal Growth Thoughts. Renewal Technologies Inc, 1(2). English for Specific Purposes World, an Open Access Journal. http://esp-world.info/Articles/,2017.

[27] Farooque, I., Mustafa, S., \& Mohammad, F. (2014). Learning style preferences of first year undergraduate medical students. $J$ Evid Based Med Health, 1, 1445-52.

[28] Fasold, R. (1991). The sociolinguistics of society. Oxford: Basic Blackwell.

[29] Frieden, F. (1981). Speaking the client's language: The effects of Neurolinguistic Programming (predicate Matching in NLP). Journal of Counseling Psychology, 31(2), 238-248. http://dx.doi.org/10.1037/0022-0167.31.2.238.

[30] Gardner, H. (1983). Frames of mind: The theory of multiple intelligences. New York: Basic books.

[31] Habibinezhad, N., and Azizmalayeri, F., (2016). The impacts of accelerated learning and explicit instruction on the retention and application of lexical bundles in writing. Journal of Novel Applied Sciences, 5(8), 338_348.

[32] Hoekstra, K. (2009). Problem Solvers. A Greener Greendale. Teaching Children Mathematics, 16(3), 140-143.

[33] Kumaravadivelu, B. (2006). Understanding language teaching. Lawrence Earlbaum Associates Inc. Publishers: NJ, USA.

[34] Lankton, S., (1980). Practical Magic: A Translation of Basic Neuro- Linguistic Programming into Clinical Psychotherapy. P.7.

[35] Lashkarian, A., and Sayadian, S., (2015). The Effect of Neuro Linguistic Programming (NLP) Techniques on Young Iranian EFL Learners' Motivation, Learning Improvement, and on Teacher's Success. Procedia - Social and Behavioral Sciences, 199, 510-516.

[36] Lyall, D. (2002). NLP in Training: the power to facilitate. Training Journal November Issue, pp. 1219.

[37] Marwaha1, K., Bhagat, A. \& Kapoor, N. (2015). Learning style preferences of undergraduate dental students of a north Indian dental college. Indian Journal of Physiology Pharmacology, 59(32), 231-237.

[38] Merritt, A. (2013). Why learn a foreign language? Benefits of bilingualism. The Telegraph, Retrieved from http://www.telegraph.co.uk/education/educationopinion/10126883/Why-learn-aforeign-language-Benefits-of-bilingualism.html.

[39] Meier, D., (2017). Natural Language Processing. 30th Conference on Neural Information Processing Systems (NIPS 2016).

[40] Moeller, AK., (2015). Foreign Language Teaching and Learning. Aleidine Kramer Moeller. University of Nebraska-Lincoln, amoeller2@unl.edu.

[41] Mohammadi, M., \& Mousalou, R. (2012).Emotional intelligence, Linguistic intelligence, and their relevance to speaking anxiety of EFL learners. Journal of Academic and Applied Studies, 2(6), 11- 22.

[42] Moharamkhani, A., Karimi, L., \& Ahmadi, D. (2016). The Impact of Neuro Linguistic Programming (NLP) on EFL Learners' Vocabulary Achievement. Journal Of Humanities And Social Science (IOSR-JHSS), 21.

[43] NLP Ausbildung » Coaching, Business, Seminare, Beratung. http://www.bs-akademie.de/, 2017.

[44] Northumberland Community Development Network- Learning Programme. www.ncdn.org/learning-support/, 2017.

[45] Pourhossein Gilakjani, A. (2012). Visual, Auditory, Kinesthetic Learning Styles and Their Impacts on English Language Teaching. Unpublished M.A. Thesis, Islamic Azad University-Lahijan ranch.

[46] Prashnig, B. (2005). Learning styles vs. multiple intelligences. Retrieved from www.creativelearningcentre.com/.../ArticleLearning-Styles-vs-html.

[47] Razmjoo, S. A. (2008). On the relationship between multiple intelligences and language proficiency. The Reading Matrix, 8(2), 155-174.

[48] Richards, J. C. \& Schmidt, R. (2002). Longman Dictionary of Language Teaching and Applied Linguistics, Pearson Education Limited: UK.

[49] Rose, C. (2003). How memory's secrets unlocked the way to relaxed, easy learning. Retrieved from file:///C|/temp/learning/00.htm, 2014.

[50] Sadeghi, K., \& Farzizadeh, B. (2012).The relationship between multiple intelligences and writing ability of Iranian EFL learners. English Language Teaching, 5(11), 136-142.

[51] Sajjadi Rad, R. Khojasteh, L. \& Kafipour, R. (2015). The relationship between multiple intelligence and writing skills of medical students in Iran. Acta Didactica Napocensia, 7(3), 9-11.

[52] Saricaoglu, A., \& Arikan, A. (2009). A study of multiple intelligences, foreign language success and some selected variables. Journal of Theory and Practice in Education, 5(2), 110-122.

[53] Schnabel, R. (2013). Are You Visual, Auditory, Kinesthetic or AD?. Retrieved from http://www.lifebeyondlimits.com.au Life Beyond Limits, 2017.

[54] Shahi, H. (2009). The relationship between multiple intelligence and learning styles. Unpublished M.A. Thesis, University of Kashan.

[55] Silberbach, F. (2007).Liven up your training using accelerated learning and NLP professional development conference. Retrieved from www.dpgplc.co.uk, 2014. 
[56] Smith, R. (2004). Contextual Materials. Retrieved From Businessballs.Com, 2017.

[57] Stanford, P., (2003). Multiple Intelligence for Every Classroom. SAGE Jour, 39, 80_85

[58] The English-language edition of the free online encyclopedia. https://en.wikipedia.org/wiki/English_Wikipedia/ articles, 2017.

[59] Toesy, P. and Mathison, J. (2003). Neuro-linguistic programming: its potential for learning and teaching in formal education. Department of Educational Studies, University of Surrey.

[60] Vaezi, Sh. (2015), Iranian EFL learners' and teachers' sensory preferences and the learners' speaking ability. International Journal of English Language Education, 3(2), 14-27.

[61] Walqui, A. (2000). Contextual factors in second language acquisition. ERIC Clearinghouse on Languages and Linguistics, Center for Applied Linguistics.

[62] Yall, D. (2002). NLP in Training: the power to facilitate. Training Journal November Issue, pp. 1219.

[63] Zoghi, R., and Khodadust, M. (2016). The relationship between linguistic intelligence and VAK preferences of Iranian EFL learners. Unpublished M.A. Thesis, Islamic Azad University of Tabriz.

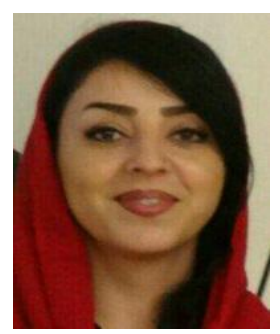

Chnour Khalandi has BA in teaching language, MA in soiciolinguistics and CELTA.She is a teacher trainer and also holding Cambridge ESOL exam preparation (Tabriz_Iran), Teacher training institute (Yeravan _Armenia). Her main areas of interest are Teacher training, Exam preparation, accelerated learning, business English and corrective feedback. She has been teaching in some internal and international institutes and also Farhanigian university of Tabriz.

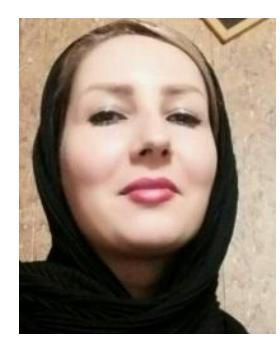

Rashideh Zoghi has BA in Art and Craft and M.A. in TEFL. She is TKT certified too. She is a teacher, sub head of Department of English Teachers in East Azerbaijan, Tabriz, Iran and supervisor in New Talent Cambridge Preparation Center in Tabriz. Her main interests are neuro linguistic programming (NLP), accelerated learning, creative teaching techniques, personality types and corrective feedback. She has been teaching in Iranian state and private secondary schools since 2002, international language institute, and Farhangian university of Tabriz. 